\title{
Editorial
}

\section{Towards a Canadian evidence base to inform action to prevent and control vaping in Canada}

\author{
Cynthia Callard, MM (1); Thierry Gagné, PhD (2); Jennifer L. O’Loughlin, PhD (3,4)
}

The upsurge in the use of electronic nicotine delivery systems (ENDS) in the past decade is a critical issue for tobacco control, characterized by rapidly changing ENDS technologies, shifting usage patterns and contradictory evidence on the added value of vaping products. Policy development in this realm is often based on risk assessments lacking replication or clear consensus on the benefits and harms of ENDS. Further, without homegrown evidence, Canada's approach has been highly reliant on the experience of and evidence in other countries, despite critical differences in regulatory landscapes and time trends in uptake across age groups. ${ }^{1}$

This second offering in a two-part series in Health Promotion and Chronic Disease Prevention in Canada: Research, Policy and Practice (the HPCDP Journal) on tobacco and vaping prevention and control presents Canadian data that directly address this knowledge gap. Our call for papers asked for new Canadian evidence on policy implementation challenges, the determinants of ENDS use, including its social distribution, and the associations between ENDS use, smoking cessation and health outcomes. The five papers in this special issue address key evidence gaps that have challenged the development of relevant policy and programs targeting ENDS use in Canada.

In an innovative online scan of vaping product retailers, D'Mello et al. $^{2}$ demonstrate the mind-boggling diversity of the online e-cigarette market in Canada in terms of nicotine concentration, availability of higher-concentration salt-base nicotine products, and flavours. The authors decry this diversity and call for reducing the number of e-liquid flavours available on the market and restricting nicotine concentrations to less than $20 \mathrm{mg} / \mathrm{mL}$. Their research reveals disturbingly high levels of noncompliance with federal regulations that prohibit the marketing of candy-flavoured e-liquids.

Two papers, one by Ahmad et al. ${ }^{3}$ and one by Shi et al., ${ }^{4}$ identify determinants of vaping initiation and daily use among Canadian youth. These papers indicate that key determinants of youth vaping in Canada likely include ease of access in addition to the constellation of vulnerabilities underpinning substance use in general, as evidenced by the close associations between vaping and other risk-taking behaviours such as cigarette smoking and use of alcohol, energy drinks and marijuana. These results corroborate supporting findings reported by Williams et al. (published in the first part of this HPCDP Journal special issue). ${ }^{5}$

Finally, two papers shed new light on the acute and long-term effects of vaping on health. First, Baker et al. ${ }^{6}$ report results from the first year of the Canadian VALI (vaping-associated lung injury) surveillance system. The authors describe encouraging numbers in terms of low occurrence and acute health consequences compared to the US. However, they caution us about our reduced capacity to monitor these outcomes since the COVID-19 pandemic, and they highlight the need to extend surveillance to assess longer-term health impacts. Second,
Pound et al. ${ }^{7}$ describe a simulation study showing the relative impact of ENDS on population health across contrasting regulatory scenarios, including a complete ban and a prescription-only scenario (i.e. wherein vaping is available to smokers only). While the debate on the benefits of vaping for cessation remains heated, this analysis underscores the high economic and health costs of delaying action to prevent vaping initiation and the subsequent transition to cigarette smoking in future generations.

We believe that, collectively, the evidence presented in this issue of the HPCDP Journal will assist regulators in enhancing interventions to decrease the recreational use of ENDS and to better control the supply of ENDS. On the demand side, the growing number of Canadian publications on youth vaping highlight that some young people are at particularly high risk of initiating and continuing use for reasons similar to those underpinning the use of other substances. In particular, the social distribution of vaping uptake was not evident early on after ENDS entered the market. ${ }^{8,9}$ However, as ENDS use progressed through the innovation curve to affect the entire population, the vulnerability characteristic of most substance use behaviours is now recognized as a key determinant of vaping uptake.

These results are highly evocative of research conducted by tobacco companies in the 1980s that aimed to identify psychographic market segments of the Canadian youth population from which they could most easily recruit new users

\footnotetext{
Author references:

1. Physicians for a Smoke-Free Canada, Ottawa, Ontario, Canada

2. Research Department of Epidemiology and Public Health, University College London, London, United Kingdom

3. Centre de recherche du Centre hospitalier de l'Université de Montréal, Montréal, Quebec, Canada

4. Département de médecine sociale et préventive, École de santé publique de l'Université de Montréal, Montréal, Quebec, Canada

Correspondence: Cynthia Callard, Physicians for a Smoke-Free Canada, 134 Caroline Avenue, Ottawa, ON K1Y OS9; Email: ccallard@smoke-free.ca
} 
using the concepts of independence, freedom and peer acceptance. ${ }^{10,11}$ This market research helped legislators recognize that comprehensive and society-wide tobacco control measures were needed to protect youth. Some of the demand-reduction interventions established for tobacco products that proved effective in reducing youth smoking (e.g. advertising bans) are now in place for ENDS, but others (e.g. plain packaging, full bans on vaping flavours) remain to be implemented.

In addition to these insights on the demand side of the equation, D'Mello's findings ${ }^{2}$ highlight stark differences between regulatory controls on the supply side of the Canadian ENDS and tobacco markets. The cigarette market is one in which virtually identical products are sold by a vertically integrated oligopoly, ${ }^{12}$ and in which manufacturers are required to provide detailed and regular reports to government on their product emissions, their ingredients, their price and their sales volume. ${ }^{13}$ In contrast, those who manufacture the many and diverse ENDS products sold in Canada are not required to file any reports with government, leaving key monitoring data unavailable. Without this information, Canadian researchers and regulators have more difficulty measuring the impact that these products have on population health.

Also on the supply side, Pound's team assessed the cost savings of shifting ENDS products from the consumer goods market and instead making them available as a therapeutic product. This regulatory innovation is underway in Australia, where e-cigarettes are now managed as "unapproved" medicines available only under prescription. ${ }^{14}$ Canada's policy choice to legalize e-cigarettes as a recreational drug product was presented as an approach that balanced concerns about "protecting youth from nicotine addiction and tobacco use, and allowing adults to legally access vaping products as a less harmful alternative to cigarettes."15 Pound's cost study suggests that there may be a better way to achieve an optimal balance.

There is now solid international and homegrown evidence that vulnerability to ENDS uptake in youth is similar to, if not higher than, that of tobacco uptake, and this has serious implications for population health in Canada. Three directions for action emerge from this set of papers. First, we can optimally protect young people by applying the set of stringent and comprehensive demand-side measures that have helped reduce tobacco initiation. Second, because Canada's ENDS market is difficult to monitor, assess and regulate, measures to bring supply under better public health management need to be prioritized. The option of limiting ENDS products to a therapeutic supply (for quitting or harm reduction) should be further explored. Third, much more evidence is needed on the short- and long-term consequences of using ENDS, a knowledge gap that can only be addressed if there is sustained support for surveillance and longitudinal research. We hope that Canada's health authorities recognize the important contribution of the five papers presented herein and use the findings to strengthen their policy and programmatic approaches to addressing the enduring public health challenge of nicotine addiction.

\section{Acknowledgements}

TG is funded by fellowship awards from the Canadian Institutes of Health Research (CIHR) and the Fonds de recherche du Québec - Santé (FRQS). JOL held a Canada Research Chair in the Early Determinants of Adult Chronic Disease from 2006 to 2021. CC benefits from Health Canada's Substance Use and Addictions Program.

\section{Conflicts of interest}

The authors declare no competing interests.

\section{Statement}

The content and views expressed in this article are those of the authors and do not necessarily reflect those of the Government of Canada.

\section{References}

1. Hammond D, Reid JL, Burkhalter R, et al. Trends in e-cigarette brands, devices and the nicotine profile of products used by youth in England, Canada and the USA: 2017-2019. Tob Control. 2021 Jun 7 [Epub ahead of print]. https://doi.org/10.1136/ tobaccocontrol-2020-056371

2. D’Mello K, Hammond D, Mahamad S, Wiggers D, East K. Nicotine content, labelling and flavours of e-liquids in Canada in 2020: a scan of the online retail market. Health Promot Chronic Dis Prev Can. 2022; 42(1):4-11. https://doi.org/10.24095 /hpcdp.42.1.02

3. Ahmad S, Wang T, Schwartz R, Bondy SJ. Predictors of pod-type e-cigarette device use among Canadian youth and young adults. Health Promot Chronic Dis Prev Can. 2022;42(1):1220. https://doi.org/10.24095/hpcdp .42 .1 .03

4. Shi J, Fu R, Hamilton H, Chaiton M. A machine learning approach to predict e-cigarette use and dependence among Ontario youth. Health Promot Chronic Dis Prev Can. 2022;42(1):21-8. https://doi.org/10.24095/hpcdp.42 .1 .04

5. Williams GC, Cole AG, de Groh M, Jiang Y, Leatherdale ST. Investigating individual-level correlates of e-cigarette initiation among a large sample of Canadian high school students. Health Promot Chronic Dis Prev Can. 2021;41(10):292-305. https://doi.org /10.24095/hpcdp.41.10.04

6. Baker MM, Procter TD, Belzak L, Ogunnaike-Cooke S. Vapingassociated lung illness (VALI) in Canada: a descriptive analysis of VALI cases reported from September 2019 to December 2020. Health Promot Chronic Dis Prev Can. 2022; 42(1):37-44. https://doi.org/10.24095 /hpcdp.42.1.06

7. Pound CM, Coyle D. A cost-utility analysis of the impact of electronic nicotine delivery systems on health care costs and outcomes in Canada. Health Promot Chronic Dis Prev Can. 2022;42(1):29-36. https://doi.org/10 $.24095 /$ hpcdp.42.1.05

8. Hartwell G, Thomas S, Egan M, Gilmore A, Petticrew M. E-cigarettes and equity: a systematic review of differences in awareness and use between sociodemographic groups. Tob Control. 2017;26(e2):e85-e91. https://doi.org/10.1136/tobaccocontrol $-2016-053222$

9. Lucherini M, Hill S, Smith K. Potential for non-combustible nicotine products to reduce socioeconomic inequalities 
in smoking: a systematic review and synthesis of best available evidence. BMC Public Health. 2019;19:1469. https://doi.org/10.1186/s12889-019 $-7836-4$

10. Pollay RW, Lavack AM. The targeting of youths by cigarette marketers: archival evidence on trial. In: McAlister L, Rothschild ML, editors. Advances in consumer research, volume 20. Duluth (MN): Association for Consumer Research; 1993. p. 266-71.

11. Pollay RW. Targeting youth and concerned smokers: evidence from Canadian tobacco industry documents. Tob Control. 2000:9(2):13647. https://doi.org/10.1136/tc.9.2.136

12. Callard CD, Collishaw N. Cigarette pricing 1 year after new restrictions on tobacco industry retailer programmes in Quebec, Canada. Tob Control. 2019;28(5):562-5.

13. Government of Canada. Tobacco reporting regulations (SOR/2000-273) [Internet]. Ottawa (ON): Government of Canada; [modified 2021 Oct 14; cited 2021 Nov 1]. Available from: https://laws-lois.justice.gc.ca/eng /regulations/sor-2000-273/index.html

14. Department of Health, Therapeutic Goods Administration. Nicotine vaping laws are changing [Internet]. Canberra (ACT): Government of Australia; 2021 Sep 3 [cited 2021 Sep 29]. Available from: https://www .tga.gov.au/blogs/tga-topics/nicotine -vaping-laws-are-changing

15. Health Canada. New tobacco and vaping products legislation receives royal assent [Internet]. Ottawa $(\mathrm{ON})$ : Government of Canada; 2018 May 23 [cited 2021 Nov 1]; [News release]. Available from: https://www.canada .ca/en/health-canada/news/2018/05 /new-tobacco-and-vaping-products -legislation-receives-royal-assent.html 